\title{
What Do Dental Students Think About Mandatory Laptop Programs?
}

\author{
William Hendricson, M.S., M.A.; Elise Eisenberg, D.D.S.; Gary Guest, D.D.S.; Pamela \\ Jones, D.D.S.; Lynn Johnson, Ph.D.; Fotinos Panagakos, D.D.S., Ph.D.; James McDonald, \\ Ph.D.; Laura Cintron, M.A.
}

Abstract: In spite of efforts by many dental schools to provide information technology resources for students, only a handful of studies have been conducted to determine what dental students think about these initiatives. There are no reports in the literature describing students' perceptions of mandatory laptop programs, which are now being implemented by at least 25 percent of North American dental schools. In schools that have implemented laptop programs, students are required either to enroll with their own laptops that meet specifications or to purchase a laptop from the school at matriculation. In some schools, students are also required to purchase curriculum support software that is bundled with the laptop. This study was conducted to determine students' opinions at U.S. dental schools with mandatory laptop programs about these aspects of this information technology initiative: frequency of use, perceived necessity of use, note-typing during lectures, effectiveness of training, influence on study habits, benefits, implementation problems, added value in relation to added tuition costs, impact on quality of dental education, overall rating of the laptop experience, and impact of the laptop on use of other electronic curriculum resources. Responses of students at schools that purchased packaged curriculum support software from a commercial vendor were compared with students' responses at schools where faculty provided their own educational software. Responses were also compared among freshmen, sophomores, and upperclassmen in a cross-sectional sample. In 2004, approximately 800 dental students at fourteen dental schools responded to eleven questions that requested their impressions and evaluation of mandatory laptop programs and associated educational software. These questions comprised one section of the IREC Students' Questionnaire (IREC=Institutional Readiness for Electronic Curriculum) that assessed students' perceptions of various aspects of information technology at their schools. The majority of students (63 percent) reported that the laptop and associated software were not essential for successful performance in their courses primarily because few instructors had modified their courses to take advantage of laptop capacities. Slightly more than half of the students reported their training was good or excellent, but felt that classroom-based "one size fits all" training was not effective. Less than 15 percent of the students reported that they had made substantial changes in their study habits as a consequence of the laptop program. The benefits perceived by students were primarily related to enhanced email communication with classmates and instructors and convenient access to the Internet and teachers' PowerPoint presentations. Implementation barriers included the inconvenience of carrying laptops to classes, lack of incentive to use the laptop and software because instructors did not require it, and poor quality software. Only 32 percent of students agreed that the value of the laptop and associated software was equal to the added tuition costs. Less than half of the students perceived that the laptop and software had improved the quality of their education, but more than 70 percent rated their overall experiences with laptops as "okay," "good," or "excellent." Freshmen expressed significantly more positive attitudes about the frequency of use, costeffectiveness, educational value, and overall quality of laptops and bundled software than did upperclassmen. A significantly higher percentage of students at schools affiliated with a software vendor reported that laptops were essential in courses than students at schools with locally produced software, but students at vendor-supplied schools rated the cost-effectiveness significantly lower. Overall, students' assessment of mandatory laptop programs was mixed although freshmen provided significantly more positive responses than did upperclassmen. Incorporation of the e-curriculum into dental schools appears to be following a similar pattern as problem-based learning (PBL) in the 1980s and 1990s. Recommendations for enhancing future e-curricula are proposed based on lessons learned from both information technology and PBL implementation.

Mr. Hendricson is Assistant Dean, Educational and Faculty Development, School of Dentistry, University of Texas Health Science Center at San Antonio; Dr. Eisenberg is Director, Dental Informatics, College of Dentistry, New York University; Dr. Guest is Assistant Dean, Predoctoral Clinics, School of Dentistry, University of Texas Health Science Center at San Antonio; Dr. Jones is Assistant Dean for Administration, School of Dental Medicine, State University of New York at Buffalo; Dr. Johnson is Director of Dental Informatics and Information Technology, School of Dentistry, University of Michigan; Dr. Panagakos was Associate Professor, Restorative Dentistry, University of Medicine and Dentistry of New Jersey-New Jersey Dental School at the time of this study; Dr. McDonald is former Associate Dean, Curriculum, School of Dentistry, Indiana University; and Ms. Cintron is Social Science Research Associate, Division of Educational Research and Development, University of Texas Health Science Center at San Antonio. Direct correspondence to William Hendricson, Assistant Dean, Educational and Faculty Development, University of Texas Health Science Center at San Antonio, School of Dentistry, 7703 Floyd Curl Drive, San Antonio, TX 78229-3900; 210-567-0436 phone; 210-567-6721 fax; Hendricson@uthscsa.edu. Reprints will not be available. 
The study reported in this article was supported by the American Dental Education Association's Council of Sections Project Pool.

Key words: dental education, instructional technology, online education, faculty development

Submitted for publication 1/6/06; accepted 2/14/06

$\mathrm{E}$ lectronic curriculum, or e-curriculum, refers to computer-based learning including providing students with educational materials on DVD, online courses, electronic mechanisms to search the literature, email, and various applications of information technology including providing laptops to students, use of computer-based simulations in preclinical lab, PDAs, multimedia projection systems, and wireless classrooms. ${ }^{1}$ Kassebaum et al. found high levels of interest among dental educators in e-curriculum. ${ }^{2}$ Eighty-six percent of North American dental schools reported that they had already expanded the use of information technology (IT) in their curricula, and 82 percent desired to increase IT even further during the next three years. Hendricson et al. reported that virtually all U.S. and Canadian dental schools had made substantial financial investments in the e-curriculum infrastructure support and resources identified in Table $1 .^{1}$ That study also found that sixteen North American dental schools in academic year 2002-03 (approximately 25 percent of all dental schools) required their students to purchase or lease laptops as a matriculation requirement and a number of these schools had contracts with a commercial vendor to supply a digital version of all curriculum materials and textbooks bundled with the required laptops.

A 2002 literature review identified nearly 600 English-language articles published in 1996-2002 that addressed computer-assisted instruction in the health professions and more than 300 articles in the same time period that more specifically addressed online (web-based) learning in health professions education or educational materials made available by CD or DVD, including twenty-nine articles that reported efforts to use e-curriculum in dental education. ${ }^{1}$ From 2003 to 2005 , twenty-three articles were published in the Journal of Dental Education that described e-curriculum applications in dental school curricula. ${ }^{1,3-24}$ From this literature and other sources, ${ }^{25-}$ ${ }^{26}$ a number of benefits of e-curriculum have been proposed (see Figure 1). A meta-analysis of 254 studies by Kulik and Kulik in 1991 indicated that computer-assisted instruction, in comparison with conventional lecture-based training, provided small learning gains (on the order of 0.3 standard devia-

Table 1. Number out of sixty-six North American dental schools that reported twelve e-curriculum infrastructure mechanisms

\begin{tabular}{|c|c|c|c|}
\hline E-Curriculum Infrastructure Support Mechanism & $\begin{array}{l}\text { Yes, } \\
\text { We Have }\end{array}$ & $\begin{array}{l}\text { Currently in } \\
\text { Development }\end{array}$ & $\begin{array}{l}\text { No, Don't } \\
\text { Have This }\end{array}$ \\
\hline Limited access intranet system for internal communication and curriculum support. & 52 & 6 & 8 \\
\hline Electronic course registration and grade assignment through the school intranet. & 32 & 10 & 22 \\
\hline Students have email accounts paid for by the school. & 65 & 0 & 1 \\
\hline Faculty have email accounts paid for by the school and Internet access in their offices. & 66 & 0 & 0 \\
\hline $\begin{array}{l}\text { Students have convenient Internet access in classrooms (accessible jacks or a wireless } \\
\text { system). }\end{array}$ & 31 & 16 & 19 \\
\hline Faculty have Internet and school intranet access at classroom podiums. & 54 & 4 & 8 \\
\hline The school or campus has a computer/multimedia laboratory. & 65 & 0 & 1 \\
\hline Students and faculty have convenient Internet access in the clinic. & 38 & 15 & 13 \\
\hline $\begin{array}{l}\text { An information technology unit that helps faculty create web-based courses and } \\
\text { multimedia materials for CD-ROM/DVD. }\end{array}$ & 46 & 4 & 16 \\
\hline $\begin{array}{l}\text { Classrooms are equipped to handle instructional technology such as multimedia } \\
\text { data projectors, laptops, and Internet access. }\end{array}$ & 62 & 4 & 0 \\
\hline Dedicated server for Blackboard and WebCT courses. & 40 & 2 & 23 \\
\hline $\begin{array}{l}\text { A staff or faculty member functions as online course manager (sets up student } \\
\text { accounts, helps faculty and students with problems). }\end{array}$ & 45 & 3 & 18 \\
\hline
\end{tabular}


- Enhances student enthusiasm and motivation.

- Enhances "anytime, anywhere" access to educational materials by students.

- Improves learning outcomes.

- Increases speed of learning.

- Increases efficiency and effectiveness of students' study habits.

- Increases student control over the pace and sequencing of learning.

- Stimulates teachers to make courses less lecture-based and more interactive.

- Improves communication and sharing between teachers and students and among students.

- Provides students with a "portal" to all materials in one interactive system.

- Provides students with better imagery and visualization.

- Allows high fidelity simulations.

- Provides research tools (electronic searching capacity).

Figure 1. Proposed educational benefits of e-curriculum

tion) and faster lesson completion among secondary and college students. ${ }^{27}$

The expectations of improved and faster learning in health professions education remain largely unmet, ${ }^{4,28-30}$ but the enthusiasm for e-curriculum continues to grow among dental educators. In spite of the substantial commitment that dental schools have already made to e-curriculum resources and the persistent advocacy for the many presumed benefits of information technology, heretofore there has been no broad-based effort, involving numerous schools, to determine the perspectives of dental students and faculty about information technology in the curriculum. To address this knowledge gap, we conducted a research study known as the Institutional Readiness for Electronic Curriculum (IREC) project with funding support from the American Dental Education Association's Council of Sections Project Pool and other sources to assess student and faculty perceptions of e-curriculum and identify strategies for effective implementation of e-curriculum. The objectives of the IREC project were to 1) determine the degree to which various e-curriculum resources have been made available to faculty and students at North American dental schools; 2) assess the level of utilization of these resources; 3) identify e-curriculum infrastructure and implementation issues, especially barriers; and 4) assess student and faculty perceptions about the effects of e-curriculum upon dental education including study habits, teaching methods, and evaluation of perceived value. The IREC steering committee consisted of dental school faculty with leadership roles in e-curricu- lum activities at their schools. Four of the steering committee members were from schools actively involved in laptop and software programs associated with Vital Source Technologies (a commercial software vendor described below), and two others were involved in their schools' own laptop initiatives using locally produced curriculum support software.

\section{Methods}

The study protocol was approved as exempted research by the Institutional Review Board at the University of Texas Health Science Center at San Antonio (UTHSCSA) on September 12, 2001 (UTHSCSA IRB Protocol \# E-012-017).

\section{Three Phases of the Study}

The IREC study consisted of three phases. Phase one was the previously described literature review on implementation of electronic curriculum in health professions education, which was summarized in $2004 .{ }^{1}$ This review was conducted to guide study design and identify areas of emphasis for phases two and three.

During IREC phase two, which was conducted during the 2002-03 academic year, the Electronic Curriculum Implementation Survey (ECIS) was completed by all sixty-six North American dental schools to accomplish three objectives: 1) identify the U.S. and Canadian dental schools that have mandatory 
laptop programs and assess cost to students, faculty development issues, extent of curricular use, problems, and qualitative perceptions; 2) determine the extent to which twenty-two other e-curriculum resources were available at U.S. and Canadian dental schools and determine the degree to which these resources were used to implement curricula; and 3) identify factors that influenced e-curriculum implementation. The results of the ECIS project were reported in the October 2005 issue of the Journal of Dental Education. ${ }^{1}$ A school was designated as having a laptop program if it had one of these policies: required students to enroll with their own laptop that met hardware and software specifications dictated by the school, required students to purchase or lease a laptop from the school at matriculation, or leased a laptop to students with a subsequent purchase option. In addition, approximately 50 percent of the laptop programs included mandatory purchase of curriculum support software by students. During the course of the IREC project (2002-04), the VitalBooks DVD created by Vital Source Technologies (VST) was the principle vendor-produced dental school curriculum resource. The VitalBooks DVD provided students with a complete digital curriculum library including key textbooks in each discipline, all course manuals, syllabi and lecture notes, lab and clinic guides, and other educational materials provided by faculty.

Based on the ECIS responses, fifteen dental schools that had already made a major commitment to e-curriculum were invited and agreed to participate in IREC phase three. The dental schools that reported a major commitment to electronic curriculum on the ECIS and were selected for phase three are hereafter referred to as the "major EC" schools. The four selection criteria used to identify the major EC schools were: 1) students were required to purchase or lease a laptop (with or without associated educational software); 2) more than 33 percent of courses were web-based and used online course evaluations; 3) at least 33 percent of faculty had received training in how to develop online courses with a course management system such as BlackBoard or WebCT; and 4) the school had access to an instructional technology unit on campus. Fourteen of the fifteen major EC schools operated mandatory laptop programs. The fifteenth school did not have a laptop program, but met the other three selection criteria: extensive use of online instruction, high level of faculty training, and access to an instructional technology support unit.
IREC phase three consisted of three questionnaires completed separately by students, course directors, and e-curriculum managers (information technology directors) at the major EC schools. Results of the students' perceptions questionnaire are reported here and in a subsequent manuscript to be submitted for publication in the Journal of Dental Education. The findings from the course directors' and e-curriculum managers' surveys will be subsequently reported. The rationale for eliciting student perceptions at these major EC schools was that this group of students had presumably experienced e-curriculum more consistently and intensely than students at other schools and thus would be in the best position to share their perceptions of the strengths, limitations, and curricular impact of information technology.

\section{Phase 3 Methods: Students' Perceptions of E-Curriculum}

Instrument Development. The IREC students' questionnaire contained sixty-three items designed to elicit the perspectives of dental students at the major EC schools and two questions that requested the name of the dental school and the student's class (academic year). The student questionnaire was developed by the IREC Project Steering Committee in 2003 based on the results of the previously described literature review, the findings from the ECIS, and recommendations of steering committee members who had substantial experience and leadership responsibilities for instructional technology at their schools. Preliminary versions of the IREC student questionnaire were critiqued by two Ph.D.-level evaluation specialists with expertise in survey design and completed by fourteen dental students at the University of Texas Health Science Center at San Antonio (UTHSCSA) to identify unclear directions, questions, or response options. After revisions based on feedback from the survey specialists and students, the questionnaire was completed by twelve more dental students at UTHSCSA to determine completion time and identify any questions that were still unclear or difficult to answer. IREC Steering Committee members also reviewed the student questionnaire during its development and provided suggestions for improvement. The student questionnaire was developed in both paper-pencil and electronic (online) formats with the later using the Survey Tracker software.

Format and Content of the IREC Students' Questionnaire. All questions employed a menu- 
driven, forced choice response format except for three open-ended write-in questions. The questionnaire had five sections as described below. This article will report findings from sections 1 and 2. Findings for sections 3-5 will be reported in a subsequent article in the Journal of Dental Education.

1. Impact of mandatory laptop programs. Approximately 800 students at fourteen dental schools provided their opinions about the educational value of laptop programs and associated curriculum support software and its impact on their study habits and overall quality of their educational experience.

2. Students' study methods. Students evaluated the impact of e-curriculum on their approaches to studying and described positive and negative experiences related to the use of laptops and educational software.

3. Use and value of other e-curriculum resources. Students rated the frequency of use and the educational value of eighteen e-curriculum capacities and methods such as selfpaced online courses, online testing, online course evaluations, email, electronic simulations, PowerPoint lectures, and web-based mechanisms for collaboration on group projects.

4. Faculty knowledge, attitudes, and teaching methods. Students assessed faculty knowledge of and attitudes about e-curriculum and the degree to which faculty had modified teaching strategies to incorporate information technology.

5. Lessons learned about e-curriculum. Students shared recommendations and insights related to implementation of e-curriculum in dental school.

Questions: Students'Perceptions of Mandatory Laptop Programs and Influence on Study Methods. Twelve questions assessed students' opinions about various aspects of the laptop programs and their influence on the students' study habits. These questions are:

1. How much have you had to use your laptop and the associated educational software to do well in your courses, e.g., learn the material and get good grades?
2. How often do you use your laptop to type notes during lecture classes?

3. What is your evaluation of the usefulness of the training you received for the laptop and associated software?

4. What are your recommendations for making laptop training more useful for students? (This question requested a write-in response.)

5. To what extent have you changed your study methods because of the laptop and its associated software?

6. What are the most positive and negative influences of the laptop program and associated software on your study methods? (This question requested a write-in response.)

7. What are the most significant benefits of the laptop program at your school? (Students selected three responses from a menu of eighteen options.)

8. What are the most significant implementation problems for the laptop program at your school? (Students selected three responses from a menu of fourteen options.)

9. Overall, the added value I receive from the laptop and its associated software has been equal to the cost that is added to my dental school tuition and fees.

10. The laptop program and associated software have improved the quality of my dental education. (Response options for this question ranged from strongly agree to strongly disagree.)

11. Up to this point in your education, how would you rate your overall experience with the laptop program?

12. Would the other electronic curriculum resources, such as web-based courses, Internet access, course websites, email with faculty and among students, wireless classrooms, and online course evaluations, be less 
effective if you did not have the laptop program at your school?

Distribution of Questionnaire and Selection of Subjects. Using a mailing list obtained from the American Dental Education Association, a package containing sixty copies of the student questionnaire, a cover letter explaining the project objectives, and an IREC information sheet approved by the UTHSCSA Institutional Review Board was mailed to the associate dean for academic affairs (ADAA) at the fifteen major EC schools that agreed to participate. Each ADAA was also sent an email with the same information and attachments that included the link to the online version of the questionnaire. The ADAAs were asked to coordinate the completion of the questionnaire with either paper-pencil or online formats by fifteen students in each class (Fr., Soph., Jr., Sr.) for a total of sixty students per school during the spring semester (January-May) 2004. The ADAAs were asked to use their discretion in selection of students from each class. The number of sixty students per school was based on the limited budget of the IREC study (staff were funded for sixteen hours a week) to handle questionnaire distribution, data entry, and statistical analysis. All major EC schools complied with the protocol after two rounds of follow-up reminders.

\section{Results}

At the time of the study, seven of the major EC schools had contracts with Vital Source Technologies (VST) to provide students with DVDs of all curriculum materials. Ten of the schools were publicly funded, and the others were private schools. Thirteen were U.S. dental schools; two were Canadian. Data analyses revealed no meaningful differences between student responses at public and private or U.S. and Canadian schools.

\section{Response Rate}

A cross-sectional sample of 866 dental students returned completed questionnaires. The response goal was 900 based on sixty students at each of the fifteen schools; thus, the response rate was 96 percent of the target (866/900). Approximately 60 percent of the students submitted paper questionnaires, and 40 percent responded online, with the response format largely determined by the preferences of the study coordinator at each school. Comparison of stu- dents submitting surveys by paper and electronically revealed no differences in response patterns other than the paper responders submitted longer write-in responses. Therefore, data from the two response formats were combined. The 866 respondents represented 25 percent of the total student enrollment at the major EC schools. Approximately 34 percent of the responding students were freshmen, 26 percent were sophomores, 23 percent were juniors, and 17 percent were seniors. The junior and senior students were combined into a single category called "upperclassmen" because of the response rate among seniors and because the answers provided by juniors and seniors were virtually identical. The upperclassmen category represented 40 percent of the overall sample. Approximately 60 percent of the responding students were enrolled at the major EC schools affiliated with VST, and 40 percent were at the other major EC schools. Overall, this cross-sectional sample of students represented 5.6 percent of the total dental student population for all North American schools in 2004. For the findings reported in this article related to students' perceptions of mandatory laptop programs and influence on study methods, approximately 800 students responded because one of the major EC schools did not operate a mandatory laptop program in the spring of 2004.

Responses to the questionnaire items are described by reporting the percentage of students who selected various options. Statistical comparisons of response frequencies between freshmen, sophomores, and upperclassmen on some of the questions were performed using the non-parametric KruskallWallis Test to determine if there was a statistically significant difference $(\mathrm{p}<0.05)$ in responses among the three student groups for these items. The MannWhitney Test was used for post hoc comparisons to determine which specific classes differed significantly from each other on questions where there was an overall statistically significant difference in response frequencies. Statistical comparisons between responses on certain items from students at schools affiliated and not affiliated with VST were also assessed via the Kruskall-Wallis and Mann-Whitney tests. ${ }^{31}$

\section{Students' Perceptions of Mandatory Laptop Programs}

Findings are summarized after statement of each question. The number of students who responded to each question ranged from 791 to 806 . 
Table 2. Student responses at major EC schools with locally produced software (local) or affiliated with Vital Source Technologies (software vendor) to the question: "How much have you had to use your laptop and the associated educational software to do well in your courses?"

\begin{tabular}{lrc} 
& Local & Software Vendor \\
\hline Essential in all courses & $9 \%$ & $22 \%$ \\
Essential in most courses & $19 \%$ & $23 \%$ \\
Not essential in most courses & $56 \%$ & $33 \%$ \\
Not essential in any course & $16 \%$ & $22 \%$
\end{tabular}

Note: The labels "local" and "vendor" refer to the main source of educational software as described below and in the text.

- Local=faculty produce own educational software for students.

- Vendor=students purchase VitalBooks DVD from VST.

How much have you had to use your laptop and the associated educational software to do well in your courses, e.g., learn the material and get good grades?

Overall, the majority of students in all three groups (freshmen, sophomores, and upperclassmen) reported that the laptop and associated software were not essential for successful performance in their courses. Collectively, 63 percent of students selected "not essential in any or most courses." However, as shown in Table 2, students at schools affiliated with VST perceived the laptops and associated software to be more essential than students at schools where faculty produced or provided their own software to students, and this difference was statistically significant $(\mathrm{p}<.028)$. Forty-five percent of students at the VST-affiliated schools, labeled "software vendor" in Table 2 and in subsequent tables, rated the laptop and bundled software as "essential in all or most courses," in comparison to 28 percent of students at schools where software was produced locally by the faculty (labeled as "local" in Table 2 and in subsequent tables). The cross-sectional data in Table 3 indicate that students' perception of the need for the laptop/software was associated with school year. Among freshmen, 65 percent of students reported that the laptop/software was "essential in all or most courses." Thirty-nine percent of sophomores responded that it was essential, but only 20 percent of upperclassmen indicated it was essential for positive academic performance. The differences in responses among the three classes of students were statistically significant $(\mathrm{p}<.001)$.
How often do you use your laptop to type notes during lecture classes?

The response options for this question were: "I type notes on my laptop in most classes," "Sometimes - depends on the subject," "rarely," and "never." Overall, 66 percent of students indicated they rarely or never typed notes on their laptops, with the remaining 34 percent selecting "in most classes" or "sometimes - depends on subject." There was no statistically significant difference in students' responses to this question between the laptop schools with locally supplied software and vendor-produced software $(p=.105)$, and there were no statistically significant differences among the three groups of students.

What is your evaluation of the usefulness of the training you received for the laptop and associated software?

The response options and overall students' answers (combining all three groups) for this question were: "excellent" (7 percent), "good" (48 percent), "only somewhat helpful" (26 percent), "not helpful" (14 percent), "no training was provided" (3 percent), and "I did not attend training" ( 2 percent). Overall, freshman and sophomore students rated the usefulness of their training significantly higher than did the upperclassmen ( $p<.011$ and $p<.010$, respectively). For example, 64 percent of the freshmen and sophomores rated the training as excellent or good in comparison to 42 percent of the upperclassmen. There was no statistically significant difference in students' ratings of training between the laptop schools with locally supplied software and the vendor-produced software.

What are your recommendations for making laptop training more useful for students?

A total of 207 students provided write-in responses to this question, and four recommendations comprised the majority of comments. There was no discernible difference in recommendations provided by students at schools with locally supplied software and vendor-produced software.

The principal recommendation for improving laptop training, provided by more than 50 percent of respondents, was to conduct a needs assessment before training to determine which students needed indepth assistance with general computer skills including word processing and Internet navigation and also to identify students who could bypass word processing and general Internet operations. Many students commented that the undifferentiated "one size fits all" laptop training implemented by most of the schools 
in this study addressed the actual needs of only a small percentage of students in the class. Far more students indicated that training was "too simple/too basic" than students who wrote that training was too advanced. The second most frequent recommendation was to individualize laptop training by conducting it in small groups where hands-on learning would be feasible and students could share suggestions with each other. Many students commented that computer training Table 3. Freshmen, sophomore, and upperclassmen responses at major EC schools to the question: "How much have you had to use your laptop and the associated educational software to do well in your courses?"

\begin{tabular}{lccc} 
& Freshmen & Sophomores & Upperclassmen \\
\hline Essential in all courses & $38 \%$ & $16 \%$ & $6 \%$ \\
Essential in most courses & $27 \%$ & $23 \%$ & $14 \%$ \\
Not essential in most courses & $30 \%$ & $38 \%$ & $49 \%$ \\
Not essential in any course & $5 \%$ & $24 \%$ & $31 \%$
\end{tabular}

classes for 50-100 students sitting in a lecture hall were not effective. The third recommendation was to conduct the laptop training in two phases: an initial "get familiar" session at the start of the fall semester, followed several weeks later by a problem-solving/ trouble-shooting session conducted in small groups to allow questions and answers. One student articulated the third recommendation by stating, "I learned far more when I came to training with specific questions after I tried to use my laptop and its loaded-up software." The fourth recommendation was an admonishment to laptop trainers to make sure that the technology actually worked before trying to demonstrate it. Approximately 40 percent of the students reported that technology glitches occurred during training including software that was not properly installed on their laptops, problems setting passwords to gain access to course websites, and connection failures in supposedly wireless classrooms.

To what extent have you changed your study methods because of the laptop and its associated software?

There were minimal differences among the three groups of students for this question, so Table 4 reflects the combined responses of the entire cross-sectional student sample. Few students at laptop schools with locally supplied software (6 percent) and vendor-produced software (18 percent) indicated that they had made major changes in their approach to studying because of the laptop and associated software. Even though the percentages of students who reported modification of study habits were small for both types of laptop programs, the difference was statistically significant $(p<.002)$ in favor of the vendor (VST) schools.

More than 400 students submitted written comments related to the question about study methods. The written responses were divided nearly equally into positive and negative commentaries about the influence of the laptop and associated software on
Table 4. Student responses at major EC schools with locally supplied software (local) or affiliated with Vital Source Technologies (software vendor) to the question: "To what extent have you changed your study methods because of the laptop and its associated software?"

\begin{tabular}{lcc} 
& Local & Software Vendor \\
\hline $\begin{array}{l}\text { Made major changes } \\
\begin{array}{l}\text { Changed a few things; made } \\
\text { some tweaks }\end{array}\end{array}$ & $6 \%$ & $18 \%$ \\
$\begin{array}{l}\text { Have not changed my study } \\
\text { methods }\end{array}$ & $55 \%$ & $51 \%$ \\
\hline
\end{tabular}

studying in dental school. The two following comments capture the essence of the pro and con perspectives expressed by students:

"Before, I would have most of my notes in a bunch of spiral notebooks and in three ring binders, and I was always forgetting where I put notes for different classes. Now I organize most of it in my laptop. It's easy and convenient and I spend less time looking for stuff."

"It's still a work in progress; studying from a laptop is more difficult for me as opposed to studying out of books and I find notetaking to be cumbersome in class. No matter what the laptop people say, staring at a fuzzy scanned image on a little laptop screen is not an ideal situation. I wound up buying most of my textbooks anyway."

What are the most positive and negative influences of the laptop program and associated software on your study methods?

Figure 2 indicates the six most frequently described positive influences of laptops on study methods and the six most often identified negative influences. Each positive or negative item was described 
Six most frequently described positive influences of the laptop program

(illustrated by direct quotes from student respondents)

- Better time management: I use my study time much more efficiently since I got this laptop.

- Access: I can access the Internet from my classrooms and labs and also use the laptop for the web and email at home.

- Convenience: Having all course files on the laptop or through the web (accessible by my laptop) makes it easier to go from source to source and text to text quickly and I lose less of my notes.

- PowerPoints: PowerPoints of lectures have been amazingly helpful, and it is more efficient to go over the PowerPoints than reading textbooks. The professors' PowerPoints are great and make the lectures clear; they let you pay attention in class rather than writing notes like crazy.

- Communication with faculty: I can communicate better and more often with my instructors and stay up with assignments and schedule changes.

- Sharing with classmates: I exchange more class notes and in general communicate more frequently with my classmates about our courses.

Six most frequently described negative influences of the laptop program

(illustrated by direct quotes from student respondents)

- Concerns about overuse and poor use of PowerPoints: The PowerPoint lectures are given way too fast and it is impossible to keep up with information, so we stop listening. Nobody can take notes when the instructors use PowerPoints because they talk nonstop and jam in too much material. We are experiencing "Death by PowerPoint" - too many, too much, too fast.

- Difficulty using software: Much of what we are given for software doesn't work as advertised. The DVD of our curriculum is buggy. The DVD that we pay for is not user-friendly, and when we're searching for a topic, often does not display the correct information because it can't find it.

- Outdated laptops: Our laptops are bottom rung, and they were outdated before we even got them.

- Don't like reading from the laptop screen: You still have to buy all the textbooks because studying off the laptop is extremely straining to the eyes and gives you headaches. Textbooks on computers are cumbersome to read, and the illustrations are hard to see.

- Wireless classrooms are often down: Our so-called wireless school is just that-"so-called." Half the time the wireless doesn't work, or it depends on where you sit in the classroom. It never works in the clinic unless you stand in a certain place in the lobby.

- Printing electronic notes is not efficient: Most of us still want and need a paper copy of our class handouts and the PowerPoints and our own typed notes because it's hard to study these things on the laptop screen, so we spend a lot of time printing and then highlighting paper copies.

Figure 2. Positive and negative influences of laptops on study methods as described by 407 students at fourteen major EC dental schools

by at least 10 percent of the 407 students who submitted comments about the influence of laptops and curriculum software on study habits. Verbatim comments written by students appear in Figure 2 to illustrate each positive and negative influence. Positive influences included better time management, Internet and email access, convenience of consolidating course materials, access to instructors' PowerPoint files, and easier/faster communication, including document sharing, with classmates and faculty. Frequently described negative influences included abuse of PowerPoints ("death by PowerPoint - too many, too much, too fast"), software-sharing glitches, outdated and underpowered laptops often described as "bottom rung" or "low bid" by students, the challenge of reading from small laptop screens, malfunctioning wireless classrooms, and lack of convenient access to "paper" copies of course materials. 
What are the most significant benefits of the laptop program at your school?

For this question, students were asked to select three responses from a menu of eighteen options. Students identified the following items as the top benefits of the laptop program: provides convenient access to the Internet (58 percent selected this item), convenient way to email lecture notes to classmates (56 percent), all study materials are conveniently in one place (36 percent), it's easier than carrying around numerous textbooks ( 25 percent), and I can create my own PowerPoints ( 20 percent). The two following benefits were each selected by less than 1 percent of students: "helps me learn more effectively" and "increased my interest in my coursework." There was no statistically significant difference in students' perception of benefits between the laptop schools with locally supplied software and vendor-produced software, and there were no statistically significant differences among the three classes of students.

What are the most significant implementation problems for the laptop program at your school?

For this question, students were asked to select three responses from a menu of fourteen potential implementation problems. Students identified the following items as the main implementation issues for the laptop program: it's a hassle to carry the laptop around (45 percent), it's distracting to have students using laptops in class (36 percent), don't need laptops and software to do well in courses (36 percent), faculty have not changed their teaching methods (29 percent), faculty rarely ask us to use the software (26 percent), and the software provided with the laptop is poor quality and hard to use ( 25 percent). Nearly 80 percent of students selected one or more of these three items: don't need laptops and software to do well, faculty have not changed teaching, and faculty rarely ask us to use software. There was no statistically significant difference in students' identification of implementation barriers between the laptop schools with locally supplied software and vendor-produced software or among the three classes.

Overall, the added value I receive from the laptop and its associated software has been equal to the cost added to my dental school tuition and fees.

The results for this question appear in Tables 5 and 6. Responses from students at the local software schools were significantly more positive than those provided by students at the schools affiliated with the software vendor $(\mathrm{p}<.002)$. Approximately 39 percent of students from the laptop schools with locally supplied software agreed or strongly agreed with this statement, in comparison with an almost equal percentage (37 percent) who disagreed or strongly disagreed (Table 5). Twenty-nine percent of students at the laptop schools with vendor-produced software agreed or strongly agreed, and 50 percent disagreed or strongly disagreed. As shown in the cross-sectional data in Table 6 , freshman students were significantly more likely to strongly agree or agree than were sophomores and upperclassmen $(\mathrm{p}<.001)$. Forty-six percent of all freshmen strongly agreed/agreed, in contrast with 25 percent of sophomores and 25 percent of upperclassmen. Conversely, 26 percent of freshmen strongly disagreed/disagreed versus 52 percent of sophomores and 58 percent of upperclassmen. Overall, combining all students who responded to this item, 32 percent of students agreed or strongly agreed, 22 percent said they could not yet evaluate, and 46 percent disagreed or strongly disagreed.

Table 5. Student responses at major EC schools with locally produced software (local) or affiliated with a software vendor to the question: "Overall, the added value I receive from the laptop and its associated software has been equal to the cost added to my dental school tuition and fees."

\begin{tabular}{lrc} 
& Local & Software Vendor \\
\hline Strongly agree & $9 \%$ & $7 \%$ \\
Agree & $30 \%$ & $22 \%$ \\
Cannot evaluate yet & $24 \%$ & $21 \%$ \\
Disagree & $20 \%$ & $21 \%$ \\
Strongly disagree & $17 \%$ & $29 \%$ \\
\hline
\end{tabular}

Table 6. Freshmen, sophomore, and upperclassmen responses at major EC schools to the question: "Overall, the added value I receive from the laptop and its associated software has been equal to the cost added to my dental school tuition and fees."

\begin{tabular}{lccc} 
& Freshmen & Sophomores & Upperclassmen \\
\hline Strongly agree & $14 \%$ & $6 \%$ & $4 \%$ \\
Agree & $33 \%$ & $19 \%$ & $21 \%$ \\
Cannot evaluate yet & $28 \%$ & $23 \%$ & $17 \%$ \\
Disagree & $16 \%$ & $26 \%$ & $21 \%$ \\
Strongly disagree & $10 \%$ & $26 \%$ & $37 \%$ \\
\hline
\end{tabular}


Table 7. Student responses at major EC schools with locally produced software (local) or affiliated with a software vendor to the question: "From my perspective as a student, the laptop program and associated software have improved the quality of my dental education."

\begin{tabular}{lcc} 
& Local & Software Vendor \\
\hline Strongly agree & $10 \%$ & $8 \%$ \\
Agree & $45 \%$ & $29 \%$ \\
Cannot evaluate yet & $21 \%$ & $21 \%$ \\
Disagree & $15 \%$ & $19 \%$ \\
Strongly disagree & $9 \%$ & $23 \%$ \\
\hline
\end{tabular}

Table 8. Freshmen, sophomore, and upperclassmen responses at major EC schools to the question: "From my perspective as a student, the laptop program and associated software have improved the quality of my dental education."

\begin{tabular}{lccc} 
& Freshmen & Sophomores & Upperclassmen \\
\hline Strongly agree & $16 \%$ & $6 \%$ & $5 \%$ \\
Agree & $39 \%$ & $30 \%$ & $29 \%$ \\
Cannot evaluate yet & $25 \%$ & $22 \%$ & $14 \%$ \\
Disagree & $13 \%$ & $21 \%$ & $24 \%$ \\
Strongly disagree & $7 \%$ & $21 \%$ & $28 \%$ \\
\hline
\end{tabular}

Table 9. Student responses at major EC schools with locally produced software (local) or affiliated with a software vendor to the question: "Up to this point in your education, how would you rate your overall experience with the laptop program?"

\begin{tabular}{lrc} 
& Local & Software Vendor \\
\hline Excellent & $8 \%$ & $5 \%$ \\
Good & $28 \%$ & $30 \%$ \\
Okay & $33 \%$ & $47 \%$ \\
In general, not positive & $16 \%$ & $12 \%$ \\
Poor; needs major improvement $15 \%$ & $6 \%$
\end{tabular}

Table 10. Freshmen, sophomore, and upperclassmen responses at fifteen major EC schools to the question: "Up to this point in your education, how would you rate your overall experience with the laptop program?"

\begin{tabular}{lccc} 
& Freshmen & Sophomores & Upperclassmen \\
\hline Excellent & $14 \%$ & $6 \%$ & $2 \%$ \\
Good & $41 \%$ & $29 \%$ & $17 \%$ \\
Okay & $32 \%$ & $39 \%$ & $41 \%$ \\
In general, not positive & $9 \%$ & $15 \%$ & $19 \%$ \\
Poor; needs major improvement & $4 \%$ & $11 \%$ & $21 \%$ \\
\hline
\end{tabular}

From my perspective as a student, the laptop program and associated software have improved the quality of my dental education.

Tables 7 and 8 display the results for this question. Overall, students at the laptop schools with locally supplied software provided significantly more positive ratings for this item than students at schools with vendor-produced software $(\mathrm{p}<.001)$. As indicated in Table 7, 55 percent of students at the laptop schools with locally supplied software strongly agreed or agreed with this statement versus 37 percent of students at schools with vendor-produced software. In contrast, 24 percent of the students at the locally supplied schools strongly disagreed or disagreed in comparison with 42 percent of students at the vendor software schools. As shown in the cross-sectional data in Table 8, freshman students were significantly more likely to strongly agree or agree than were sophomores and upperclassmen $(p<.01)$. Fifty-five percent of all freshmen strongly agreed/agreed, in comparison to 36 percent of sophomores and 34 percent of upperclassmen. Conversely, 20 percent of the freshmen strongly disagreed/disagreed versus 42 percent of the sophomores and 52 percent of the upperclassmen.

Up to this point in your education, how would you rate your overall experience with the laptop program?

Responses for this question are displayed in Tables 9 and 10. The responses from students at laptop schools with locally or vendor-produced software were significantly different $(p<.042)$. Essentially the same percentage of students at both schools rated the laptop program as excellent or good although 31 percent of students at the vendor-produced software schools rated the program as "in general, not positive" or "poor; needs major improvement" versus 18 percent of students at the local software schools (Table 9). The cross-sectional data in Table 10 indicate that freshmen rated their overall laptop experience more positively than either sophomores or upperclassmen. Approximately 55 percent of freshmen rated the program as excellent or good in comparison to 34 percent of sophomores and 19 percent of upperclassmen; the differences 
between classes were statistically significant $(\mathrm{p}<.001)$. Overall, combining all students who responded to this item, 35 percent of students agreed or strongly agreed, 37 percent said they could not yet evaluate, and 28 percent disagreed or strongly disagreed.

Would the other electronic curriculum resources such as web-based courses, Internet access, course websites, email with faculty and among students, wireless classrooms, and online course evaluations be less effective if you did not have the laptop program at your school?

Tables 11 and 12 provide the students' responses to this question. Approximately half of the students at the laptop schools with faculty-produced and vendor-supplied software indicated that other ecurriculum components would be less effective without the laptop to facilitate access to these IT capabilities (Table 11). However, an almost equal percentage of students in both categories of laptop schools felt that other e-curriculum capacities such as web-based courses, course websites, email among faculty and students, and online course evaluations would be still effective, although less convenient, or equally effective without a mandatory laptop program. Overall, the responses from students at the laptop schools with faculty-produced and vendor-produced software were not significantly different. As demonstrated in the cross-sectional response patterns for other questions (Table 12), freshman students were the most likely to select "less effective without my laptop" (58 percent) in comparison to sophomores (46 percent) and upperclassmen (35 percent). The response of freshmen was significantly different from that of the upperclassmen $(p<.001)$ but not from sophomores $(p<.081)$. The responses of sophomores and the upperclassmen were also significantly different $(\mathrm{p}<.028)$.

\section{Discussion}

The discussion section is divided into three parts: 1) summary of the study methodology and rationale, 2) our perspectives on noteworthy findings, and 3) assessment of organizational change issues pertinent to e-curriculum.
Table 11. Student responses at major EC schools with locally produced software (local) or affiliated with a software vendor to the question: "Would other ecurriculum resources such as web-based courses, Internet access, course websites, email with faculty and among students, wireless classrooms, and online course evaluations be less effective if you did not have the laptop program at your school?"

\begin{tabular}{lcc} 
& Local & Software Vendor \\
\hline $\begin{array}{l}\text { Less effective without my } \\
\quad \text { laptop }\end{array}$ & $47 \%$ & $51 \%$ \\
$\begin{array}{l}\text { Would be less convenient, } \\
\quad \text { but still effective }\end{array}$ & $32 \%$ & $23 \%$ \\
No difference in effectiveness & $20 \%$ & $26 \%$ \\
\hline
\end{tabular}

Table 12. Freshmen, sophomore, and upperclassmen responses at fifteen major EC schools to the question: "Would other e-curriculum course evaluations be less effective if you did not have the laptop program at your school?"

Less effective without my laptop Would be less convenient, but still effective

o difference in effectiveness Cannot respond; my school does not have laptop program

\begin{tabular}{ccc} 
Freshmen & Sophomores & Upperclassmen \\
\hline $58 \%$ & $46 \%$ & $35 \%$ \\
$19 \%$ & $25 \%$ & $28 \%$ \\
$15 \%$ & $22 \%$ & $29 \%$ \\
$8 \%$ & $7 \%$ & $8 \%$
\end{tabular}

\section{Study Methodology and Rationale}

At least 25 percent of all North American dental schools have implemented mandatory laptop programs since 2000, but there are no reports in the literature that we could identify that described students' perceptions of these programs. This component of the IREC study was conducted to address this knowledge gap by determining students' opinions at fourteen U.S. dental schools with mandatory laptop programs about various aspects of this information technology initiative. Responses were compared between students at schools that purchased packaged curriculum support software from a commercial vendor versus schools where faculty provided their own educational software, and responses were compared among freshmen, sophomores, and upperclassmen in a cross-sectional sample. The results of the previous ECIS project, described in the introduction, suggest that these fourteen schools were at the leading edge of information technology adoption (e.g., char- 
acterized as "early adopters" in organization development literature) among U.S. dental schools at the time of this study. ${ }^{1}$ ECIS findings demonstrate that these major electronic curriculum schools had made substantially greater efforts to provide information technology resources and capabilities, as described in Table 1, such as online course management systems, dedicated IT support staff, and web-based course evaluations for students and faculty than had other schools. Thus, we felt that examination of student perceptions at these "early adopter" schools may provide unique insights that will enhance the IT implementation efforts of other schools that appear to have taken a "wait and see" approach to electronic curriculum. The 800 students who participated in this study also represent the largest sampling of dental students' opinions about e-curriculum reported to date and has the advantage of reflecting the views of students at a substantial number of dental schools rather than just one.

\section{Noteworthy Findings and Interpretation}

The results will provide some degree of comfort for advocates of required laptop programs and also for skeptics of this particular information technology initiative. Five findings are particularly noteworthy from our perspective and are discussed in rough order of importance.

First, students' assessment of mandatory laptop programs was less than enthusiastic overall, but freshmen, particularly, and sophomores, to some extent, provided more positive assessments of laptop programs than upperclassmen. The generally positive response of freshmen in contrast to upperclassmen can be interpreted in several ways because data was collected from a cross-sectional sample rather than a longitudinal sample that followed one class through the four years of dental school. One interpretation of the differences in response patterns among classes is that faculty have learned to more effectively take advantage of laptop/software capacities over the past three to four years. At many of the schools in this study, the upperclassmen who participated were the first students at their school to be part of a mandatory laptop program, and at the VST-affiliated schools, they were the first students to experience that curriculum support software. Predictably, initial efforts to use the laptop/software in the curriculum may not have been well orchestrated, an issue that is reflected in the upperclassmen's generally negative assessments; but with practice and tweaking by faculty, implementation may have been more effective for the freshmen as reflected by their responses. An alternative explanation is that upperclassmen are rarely required to use their laptops and bundled educational software in the clinical phase of dental school (as was often reported in the writein comments of juniors and seniors), and thus their responses reflect a perception that the laptop is of little current value in the clinic.

Our assessment is that both explanations have an element of truth: most studies of curricular change demonstrate that implementation of instructional innovations does become more effective over time if the innovation is not abandoned after the initial, and often flawed, implementation, ${ }^{1,32-33}$ and the upperclassmen who participated in this study probably had little use for their laptop as a study aid in the clinical years. More than 60 percent of the write-in comments by upperclassmen mentioned the lack of practical utility of the laptop. For example, one senior student wrote this comment, which was typical of many others:

"I don't really remember the last time I actually used my laptop or the DVDs and to be honest I haven't even thought about them for a long time until I started to do this survey. My guess is that a lot of our clinic teachers don't even know about the laptop or the DVD. I have never had an instructor mention them during almost two years in the clinic."

However, we believe it is important to note that a number of upperclassmen as well as some underclassmen commented that gaining some in-school experience with information technology would likely enhance their comfort and familiarity with electronic records and computer-based office management systems when they started practice.

The second noteworthy finding was that students in all classes reported there was minimal necessity to use laptops/educational software to perform well (get good grades) in their courses. This feeling reinforces the students' perception that their instructors have made minimal effort to build learning experiences into courses that require use of the laptop, for example, asking students to use their laptops in a wireless classroom to access an Internet site with patient simulations. These students' writein comments exemplify this perception:

"It's pretty apparent that there a lot of things that our professors could ask us to do with 
these laptops or on the Internet in class or as homework assignments but they don't."

"It's nice to be able to look at the teacher's PowerPoints on my screen during class and then to have the PowerPoints available at home to study later, but other than that, none of my professors has done much with the laptop other than make jokes about emailing and googling during class."

"I guess they're happy with the way things are, and to be honest, I'm not sure how the DVD would help me do better on tests. Studying the PowerPoints and my own lecture notes and reading parts of the text mentioned by the professor in class are enough to be prepared."

However, a significantly higher percentage of students at schools affiliated with VST reported that the laptop and associated software were essential for good performance. This finding suggests that meaningful integration of e-curriculum may be enhanced by a comprehensive schoolwide strategy in which all faculty and students are provided one educational resource (in this case, the VitalBooks DVD) that can be used throughout the curriculum versus allowing faculty to devise their own software based on individual perceptions of need. There is evidence from research on incorporating informational technology into complex business and academic institutions that a "transformational" strategy that is comprehensive (all teachers participate) and not negotiable (implementation is required and not optional) is more likely to produce high levels of utilization and meaningful changes in curriculum format than following an "evolutionary" approach in which teachers learn to make use of an IT innovation by trial and error experimentation on their own and can be selective about implementation. ${ }^{34-35}$ Although it is our impression that no dental schools in this study overtly required their faculty to use the laptop and bundled VST software in specific ways, contracting with a software vendor to provide a universal product to support the entire curriculum is certainly more of a "transformational" approach than asking students to purchase laptops but leaving it up to faculty to produce/acquire their own software. Thus, the stronger perception of performance utility among students at VST-affiliated schools might be a reflection of a decision by these schools to follow a strategy more consistent with transformation than evolution. On the other hand, it is important to note that less than 50 percent of students at VST-affiliated schools reported that the laptop and bundled software were essential or very essential for good performance. Therefore, even at schools that apparently implemented a proactive transformational strategy for information technology, the connection in the students' minds between good performance and use of the laptop/software was not particularly strong.

The third noteworthy finding was that, overall, the majority of students were not convinced that the laptop program and associated software added sufficient educational value to justify the increased tuition. Students at schools with locally produced software had significantly more positive perceptions about the educational value added by the laptop program than students at vendor-supplied schools, but, overall, less than 40 percent of students at both categories of schools responded positively (32 percent). This finding combined with data displayed in Table 2 (necessary for good grades), Table 7 (improved quality of dental education), and Table 9 (overall evaluation of laptop program) in which less than 50 percent of all students responded positively to each of these items, coupled with students' perceptions of implementation problems (e.g., faculty have not changed teaching methods), suggests that the majority of students in this study did not perceive the laptop program as a "difference-maker" in their dental education and consequently had concerns about the additional financial burden. This finding has implications for the admissions process and faculty development. Unless academic program managers can convince/encourage faculty to more proactively incorporate e-curriculum into courses in an educationally effective manner, so that students see a tangible benefit and are thus motivated to use these resources, the long-term effect on school attractiveness, including tuition cost, among prospective applicants may need to be examined. However, our assessment is that the responses of the freshman and sophomore students are the most likely representation of current student attitudes about mandatory laptop programs and the value of associated curriculum support software. The perceptions of the underclassmen in this study, particularly the freshmen, during the spring semester 2004 provide a somewhat optimistic view of what students think about e-curriculum.

The fourth noteworthy finding was that few students reported they had modified their study habits. Students' responses to the question about implementation barriers, their assessment of the negative 
aspects of the laptop program (Figure 2), and the analysis of persistent themes in their write-in comments all point to the fact that most of their faculty had not changed teaching methods to incorporate laptop-related activities other than as a mechanism to share PowerPoint files. This finding is particularly notable because thirteen of the fourteen schools represented in this study had operated mandatory laptop programs for at least three years at the time of the study. Student reports that dental school faculty had made few curricular modifications to take advantage of laptop and educational software capabilities reinforce previous findings that faculty hesitancy to change instructional methods is often a profound barrier to integration of information technology and adoption of other curriculum modifications in health professions education programs. ${ }^{1,36-37}$ For example, in the preceding ECIS study, dental school administrators identified faculty reluctance to change coupled with lack of training and support for instructors as the principal barriers to e-curriculum implementation. ${ }^{1}$ Faculty hesitancy to embrace e-curriculum is not a new phenomenon; it simply continues a decades-long pattern. Faculty in the 1940s were slow to adopt simple audiovisual devices, such as overhead and slide projectors, designed to make life easier in the classroom. Teachers at secondary, college, and graduate/professional school levels demonstrated similar approach-avoidance behavior for film in the 1950 s, videotape in the 1960s, searchable videodisk technology in the 1970s, computer-assisted learning (at desktop computer stations) in the 1980s, and early versions of web-based learning with hyperlinking and email capabilities in the $1990 \mathrm{~s} .{ }^{35}$ Information technology innovations for the past five decades have been proposed as mechanisms to allow individualization of students' learning experiences, diversify the time, place, and rate of learning, and serve as ways to break the "sage on the stage" (teacher/lecturer-centered instruction) mold that has dominated higher education since the medieval period. In spite of persistent advocacy for information technology and learner-centered curriculum models, primarily problem-based learning (PBL), the sage on the stage model still reigns supreme in most dental and medical schools although academic program managers desire to diversify learning experiences., ${ }^{2,38-43}$

Previous investigations of personality profiles, preferred learning styles, and study habits over the past twenty-five years consistently found that dental students are concrete learners who are comfortable in a teacher-centered learning environment and expect a well-organized, efficient curriculum with clear objectives. ${ }^{44-48}$ For example, Murphy et al. concluded that dental students prefer to learn by attending lectures and prefer instructors who 1) use detailed visuals to augment their verbal presentations and 2) facilitate students' note-writing during class with guided lecture notes and handouts. ${ }^{48}$ In contrast, the responses to the question about note-taking in class suggests that the students participating in this study did not see the laptop as facilitating better note-writing. Our collective experience indicates that dental students are, above all, pragmatic and results-oriented and not likely to change their study methods unless they are convinced that an alternative approach is clearly superior and will be time/effort-effective. The findings from this study suggest that faculty have not yet made the case that use of a laptop and associated software substantially improves academic performance.

The fifth noteworthy finding was that many students perceived a "better way" to conduct training related to use of the laptop and associated software, even though the overall ratings of the laptop training were generally positive, especially among freshmen. Students reported that the most common training model was an undifferentiated approach in which all students received the same instruction, usually in a large-group, classroom setting, without a needs assessment to identify students who were computer neophytes versus those who already possessed well-developed computer skills. The most frequently expressed recommendations by the 207 students who submitted written comments about laptop training were: 1) individualize training based on the student's unique needs; 2) conduct hands-on training in small groups in computer labs; 3) minimize emphasis on routine word processing and Internet skills that virtually all students already possess; and (4) conduct follow-up sessions several weeks into the curriculum with a problem-solving focus. Nearly one-third of the students' written comments included observations about the need to provide training for faculty including the following comment that exemplified this theme:

"What they did for us [students] was all well and good and I learned a couple of things, but looking back I think the time would have been much better spent if the training was given to the faculty instead of us students. In most of my classes the students know more about the DVD, Internet and the other software we were given than the instructors who mostly just ignored all of those things." 


\section{Organizational Change Issues Pertinent to E-Curriculum}

Failure to meaningfully integrate information technology into educational programs is not unique to health professions education. Zemsky and Massey, in a study titled "Thwarted Innovation: What Happened to E-Learning and Why," investigated e-learning (defined similarly to e-curriculum) at six colleges and universities that had made major investments in information technology ranging from small liberal arts campuses such as Hamilton College with less than 2,000 students to major public universities such as the University of Texas-Austin and Michigan State University with thousands of students. ${ }^{49}$ This eighteen-month study explored three assumptions that have driven efforts to reform higher education through the application of information technology. The investigators' conclusions about the validity/accuracy of these assumptions are indicated in italics.

- If we build it, they will come. Not True. Despite massive investments in both hardware and software, there has yet to emerge a viable market for e-learning products other than online course management systems such as WebCT and Blackboard and PowerPoint lectures which are the electronic equivalent of clip-art.

- Students will take to e-learning like ducks to water. Only Partially True. Students do want to be connected, but principally to one another; e-learning at its best is seen [by students] as a convenience and at its worst as a distraction.

- E-learning will force a change in the way we teach. Not True. Not by a long shot; even when they use e-learning products and devices, most faculty still teach as they were taught: they stand in the front of a classroom providing lectures.

Zemsky and Massey concluded, "E-learning will only become pervasive when faculty change how they teach - not before." ${ }^{\prime 99}$ Thus, from our perspective, the primary question, and challenge, facing advocates of e-curriculum is how to change deeply ingrained instructional behavior by implementing an institutional change process (transformation) that makes alternative teaching strategies desirable to faculty. Based on a model of innovation transfer within complex organizations originally proposed by Szulanski, ${ }^{50}$ Hendricson et al. described four stages in the transformation of operational methods or routines as they apply to curriculum implementation (Figure 3 ). ${ }^{1}$ Transfer is the process by which an organization develops and attempts to institutionalize new methods to accomplish its missions; for example, implementing a laptop program so students can access educational websites in wireless classrooms and have electronic versions of all course materials instantly available. The four stages of the transfer process are initiation (conception and pre-implementation planning), initial implementation efforts (characterized by "on the job" trial and error learning), ramp-up to satisfactory performance, and integration with established routines. During the initiation phase, decision makers decide to implement a new strategy or methodology to accomplish an organizational goal and then start preliminary planning by a small group of inner circle advocates who support the innovation. The new routine is ultimately unveiled for use by many other individuals in the organization who typically are not well informed about the new approach. This stage involves resolution of problems that arise during first implementation attempts by individuals, called the outer circle, who were not involved in planning and who may not share the assumptions, enthusiasm, or skills of the inner circle and thus may experience difficulties in using the new routine, particularly in the absence of training. Transformation efforts that survive initial implementation evolve into a ramp-up phase where the organization attempts to produce successes that justify the innovation and motivate non-users to join the effort. During the integration phase, the innovation is absorbed into the organizational culture as a standard operational procedure and is no longer perceived to be new or different. This four-stage transfer process may take many years to complete, depending on the complexity of the innovation, the degree of resistance or apathy among the outer circle, and the management skills of organizational leaders. ${ }^{51-52}$

According to Szulanski, innovations can become stuck at each of the four stages, but are most likely to experience problems or even failure during the initial implementation stage, as highlighted in Figure 3, for the following reasons: 1) poor communication between the inner circle advocates and the outer circle who are expected to implement the innovation; 2) lack of motivation among the outer circle; 3 ) failure to prepare the outer circle for new tasks and roles; and 4) failure to provide encouragement and rewards for the outer circle, especially as they struggle with the predictable but discouraging pitfalls..$^{53}$ The students' perceptions reported in this article combined with the findings from the previous ECIS study ${ }^{1}$ suggest that dental schools are having difficulties with the "hand-off" of e-curriculum 


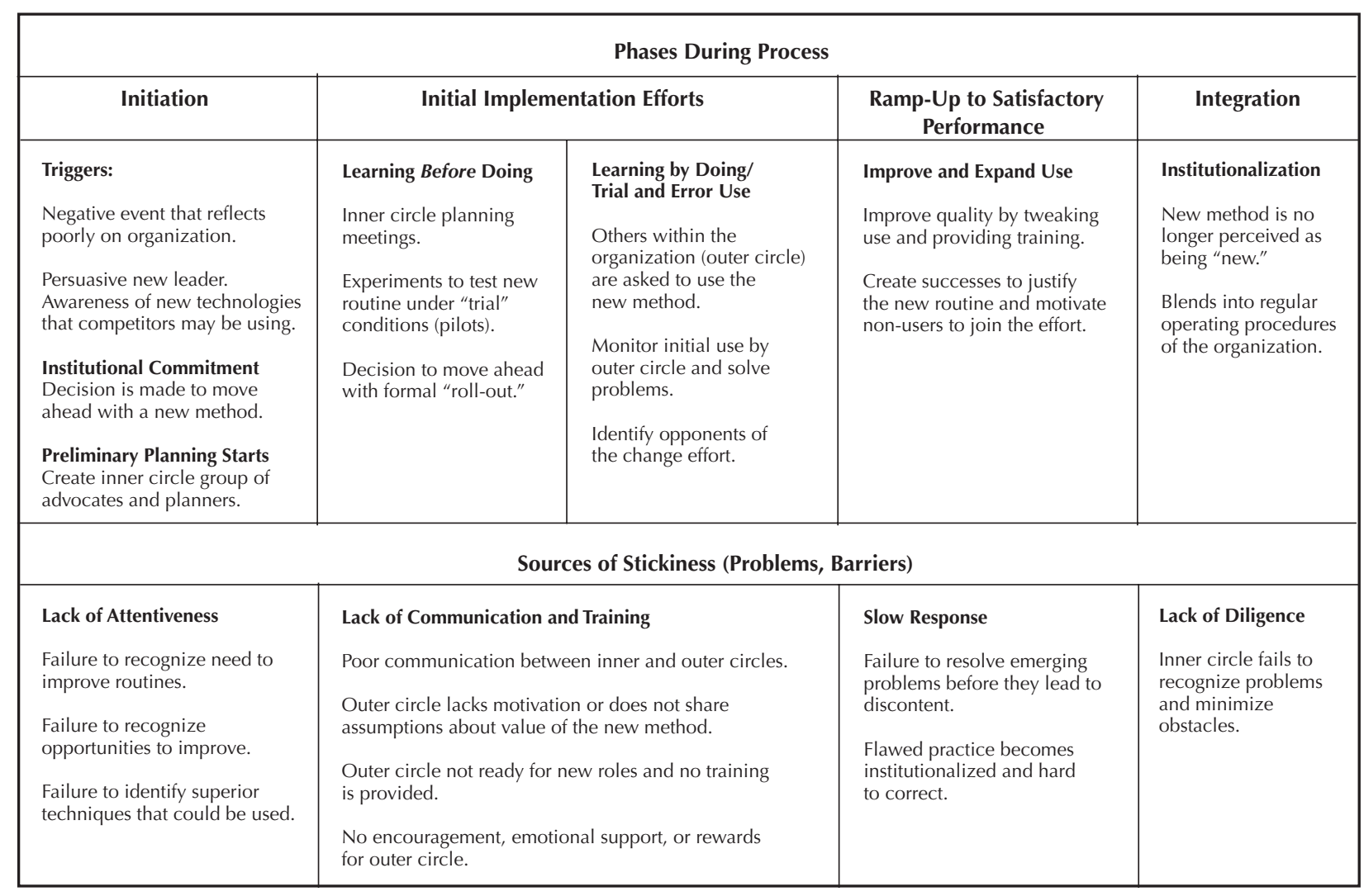

Based on: Szulanski G. The process of knowledge transfer: a diachronic analysis of success. Org Behav Hum Decision Processes 2000;82(1):9-27.

Figure 3. Phases during implementing a new operational routine and sources of problems during each phase

from the inner circle of faculty and administrators who are enthusiastic about the potential of information technology to accomplish the benefits depicted in Figure 1 to the faculty in general who appear to be displaying characteristic outer circle behavior.

The struggle to incorporate e-curriculum into dental school historically parallels the reaction of dental school faculty to problem-based learning in the 1980s and 1990s. Hendricson and Cohen ${ }^{40}$ identified factors that mitigated against adoption of PBL in dental schools: 1) the student-centered structure of PBL was alien to virtually all dental school faculty who had no experience with case-based and discussionbased learning when they were students; 2) department chairs had concerns about the resources needed to implement PBL and consequently were hesitant to commit their teachers to a curriculum format that was perceived to be faculty intensive; 3) PBL was often used as an "add-on" supplement to an already over- crowded curriculum to help students tie together basic science and clinical concepts, but no free time was created for students to do the independent research that is the heart and soul of the PBL process and thus students perceived it to be an extra burden with little tangible reward; 4) many dental school faculty were not comfortable with the "solve the mystery" process of PBL (essentially a diagnostic detective game) and had difficulty relating to students who wanted to debate the merits of various patient care approaches, which faculty saw as time consuming and inefficient; and 5) faculty repeatedly asked to be shown the evidence that PBL is a sound methodology but did not receive convincing answers that there was sufficient educational gain to rectify the perception that PBL was "more work for the already overworked." The findings of the previous ECIS study and those reported here suggest that e-curriculum is following a similar path. Many of the reasons why PBL failed to make 
inroads in dental schools appear to be recurring, although the responses of the freshmen students are somewhat encouraging. Critiques of the PBL movement concluded that adoption of this educational innovation would have been enhanced by three events that largely did not occur: 1) avoid the "build it and they will come" approach by providing meaningful training to faculty prior to implementation of this curriculum model; 2) establish that the technique is indeed worth the extra effort by conducting research that proves that assumptions about educational advantages are true; and 3) once events 1 and 2 have occurred, implement a transformational approach to ensure a comprehensive implementation of the innovation throughout the curriculum versus the evolutionary approach that typically relegates curriculum innovations to the category of supplements and add-ons..$^{54-57}$

Dental schools considering implementation of mandatory laptop programs and other types of e-curriculum would be well served to follow these recommendations.

\section{Conclusion}

Overall, a cross-sectional sample of approximately 800 students at fourteen U.S. dental schools with a major commitment to information technology provided a mixed assessment of the value and practical utility of mandatory laptop programs. Students reported there was minimal necessity to use laptops and associated software to do well in their courses, and few students reported changes in study methods because they perceived that most of their instructors had not modified courses to incorporate laptop-related activities. The benefits perceived by students were primarily related to enhanced email communication with classmates and instructors, convenient access to the Internet, and ability to receive their teachers' PowerPoints. Less than one-third of students agreed that the value of laptop and associated software were equal to the added tuition costs.

However, there were three findings that may be encouraging to advocates of e-learning in dental school. First, freshmen expressed significantly more positive attitudes about the frequency of use, costeffectiveness, educational value, and overall quality of laptops and bundled software than did upperclassmen. Second, in spite of the fact that students at vendor-supplied schools rated the cost-effectiveness of the laptops/software significantly lower than students at schools not affiliated with a vendor, a significantly higher percentage of students at the vendor schools reported that laptops were essential in courses than students at the other schools participating in this study. Third, despite being generally negative about this educational innovation, many upperclassmen commented that gaining experience with e-curriculum ultimately may be beneficial when they enter practice in terms of increasing their familiarity and comfort with IT applications in the dental office.

Overall, the students' responses suggest that dental schools are experiencing implementation difficulties similar to those encountered with PBL, and the pattern of faculty reaction is also similar to what occurred when other types of information technology emerged over the past fifty years. Based on previous studies of innovation adoption, we conclude that establishing an evidence base that supports use of e-curriculum, increasing emphasis on faculty development, and employing a transformational implementation strategy may improve incorporation of information technology into the mainstream curriculum in the future.

\section{REFERENCES}

1. Hendricson WD, Panagakos F, Eisenberg E, Guest G, Jones P, Johnson L, et al. Electronic curriculum implementation at North American dental schools. J Dent Educ 2004;68(10):1041-57.

2. Kassebaum D, Hendricson W, Taft T, Haden K. The dental curriculum at North American dental institutions in 2002-03: a survey of current structure, recent innovations, and planned changes. J Dent Educ 2004;67(9):914-31.

3. Andrews KG, Demps EL. Distance education in the U.S. and Canadian undergraduate dental curriculum. J Dent Educ 2003;67(4):427-38.

4. Rosenberg H, Grad HA, Matear DW. The effectiveness of computer-aided, self-instructional programs in dental education: a systematic review of the literature. J Dent Educ 2003;67(5):524-32.

5. Cohen HB, Walker SR, Tenenbaum HC, Spero L. Interdisciplinary, web-based, self-study interactive programs in the dental undergraduate program: a pilot. J Dent Educ 2003;67(6):661-8.

6. Littlefield JH, Demps EL, Keiser K, Chatterjee L, Yuan $\mathrm{CH}$, Hargreaves KM. A multimedia patient simulation for teaching and assessing endodontic diagnosis. J Dent Educ 2003;67(6):669-77.

7. Schleyer TKL. Dental informatics: an emerging biomedical informatics discipline. J Dent Educ 2003;67(11):11931200.

8. Johnson LA, Schleyer TKL. Developing high-quality educational software. J Dent Educ 2003;67(11):1209-20.

9. Schleyer TKL, Johnson LA. Evaluation of educational software. J Dent Educ 2003;67(11):1221-8.

10. Gray SA, Deem LP, Sisson JA, Hammrich PL. The predictive utility of computer-simulated exercises for pre- 
clinical technique performance. J Dent Educ 2003; 67(11):1229-33.

11. Abbey LM, Arnold P, Halunko L, Huneke M, Lee S. Case studies for dentistry: development of a tool to author interactive, multimedia, computer-based patient simulations. J Dent Educ 2003;67(12):1345-4.

12. Gordon JS, Severson HH, Seeley JR, Christiansen S. Development and evaluation of an interactive tobacco cessation CD-ROM educational program for dental students. J Dent Educ 2004;68(3):361-9.

13. LeBlanc VR, Urbankova A, Hadavi F, Lichtenthal RM. A preliminary study in using virtual reality to train dental students. J Dent Educ 2004;68(3):378-83.

14. Mendonca EA. Clinical decision support systems: perspectives in dentistry. J Dent Educ 2004;68(6):589-97.

15. Kim S, Mouradian WE, Leggott PJ, Schaad DC, Shaul C. Implications for designing online oral health resources: a review of fifty-six websites. J Dent Educ 2004; 68(6):633-43.

16. Olson BL, McDonald JL. Influence of online formative assessment upon student learning in biomedical science courses. J Dent Educ 2004;68(6):656-9.

17. Bogacki RE, Best A, Abbey LM. Equivalence study of a dental anatomy computer-assisted learning program. J Dent Educ 2004;68(8):867-71.

18. Jasinevicius TR, Landers M, Nelson S, Urbankova A. An evaluation of two dental simulation systems: virtual reality versus contemporary non-computer-assisted. J Dent Educ 2004;68(11):1151-62.

19. Boberick K. Creating a web-enhanced interactive preclinic technique manual: case report and student response. J Dent Educ 2004;68(12):1245-57.

20. Buchanan JA. Experience with virtual reality-based technology in teaching restorative dental procedures. J Dent Educ 2004;68(12):1258-65.

21. Holtzman JM, Elliot N, Biber CL, Sanders RM. Computerized assessment of dental student writing skills. J Dent Educ 2004;69(2):285-95.

22. Johnson JT. Creating learner-centered classrooms: use of an audience response system in pediatric dentistry education. J Dent Educ 2004;69(3):378-81.

23. Rajab LD, Baqain ZH. Use of information and communication technology among dental students at the University of Jordan. J Dent Educ 2004;69(3):387-98.

24. Holyfield LJ, Bolin KA, Rankin KV, Shulman JD, Jones DL, Despain Eden B. Use of computer technology to modify objective structured clinical examinations. J Dent Educ 2004;69(10):1133-6.

25. Curry M, Smith L. Twelve tips for authoring online distance learning medical post-registration programmes. Med Teach 2005;27(4):316-21.

26. Billings D, Connors H, Skiba D. Benchmarking best practices in web-based nursing courses. Adv Nurs Sci 2001; 23:41-52.

27. Kulik CC, Kulik JA. Effectiveness of computer-based instruction: an updated analysis. Comp Hum Behav 1991; 7:75-94.

28. Chumley-Jones H, Dobbie A, Alford C. Web-based learning: sound educational method or hype? A review of the evaluation literature. Acad Med 2002;77(10):S86-S93.

29. Bissell V, McKerlie RA, Kinanae DF, McHugh S. Teaching periodontal pocket depth charting to dental students: a comparison of computer-assisted learning and traditional tutorials. Br Dent J 2003;195(6):333-6.

30. Aly M, Elen J, Willems G. Instructional multimedia program versus standard lecture: a comparison of two methods for teaching the undergraduate orthodontic curriculum. Eur J Dent Educ 2004;8(1):43-6.

31. Conover WJ. Practical nonparametric statistics. $2^{\text {nd }}$ ed. New York: John Wiley and Sons, 1980.

32. Bates AW. Managing technological change. San Francisco: Jossey-Bass, 2000.

33. Brookfield S. Becoming a critically reflective teacher. San Francisco: Jossey-Bass, 1995.

34. Ford P, Goodyear P, Heseltine R, Lewis R, Darby J, et al. Managing change in higher education: a learning environment architecture. Buckingham, UK: Society for Research into Higher Education and Open University Press, 1996.

35. Darby J. E-learning as a change agent. Int J Comp Internet Management 2004;12(2):171-6.

36. Bland CJ, Starnamann S, Wersal L. Curricular change in medical schools: how to succeed. Acad Med 2000;75: 575-94.

37. Palloff RM, Pratt K. Beyond the looking glass: what faculty and students need to be successful online. In: Rudestam KE, Schoenholtz-Read J., eds. Handbook of online learning. London: Sage Publications, 2004:171-84.

38. Tedesco LA. Issues in dental curriculum and change. J Dent Educ 1995;59:97-147.

39. Hendricson W, Cohen P. Future directions in dental school curriculum, teaching, and learning. In: Haden K, Tedesco L. Leadership for the future: the dental school in the university. Washington, DC: American Association of Dental Schools, Center for Educational Policy and Research, 1999:37-62.

40. Hendricson WD, Cohen PA. Oral health care in the $21^{\text {st }}$ century: implications for dental and medical education. Acad Med 2001;77(12):1181-206.

41. Bertolami CN. Rationalizing the dental curriculum in light of current disease prevalence and patient demand for treatment: form vs. content. J Dent Educ 2001;65(8):725-735.

42. DePaola DP, Slavkin HC. Reforming dental health professions education: a white paper. J Dent Educ 2004; 68(11):1139-50.

43. Behar-Horenstein LS, Mitchell GS, Dolan TA. A case study examining classroom instructional practices at a U.S. dental school. J Dent Educ 2005;69(6):639-48.

44. Silberman SL, Cain MJ, Mahan JM. Dental students' personality: a Jungian perspective. J Dent Educ 1982; 46(11):646-51.

45. Suddick RP, Herbert RJ, DeMaris DM. Personality traits of dental students as determined by the clinical analysis questionnaire. Paper presented at the International Association of Dental Research/American Association for Dental Research, Las Vegas, Nevada, March 21, 1985.

46. Berlocher WC, Hendricson WD. Student and faculty learning styles. J Dent Educ 1985;49(10):684-8.

47. Hendricson WD, Berlocher WC, Herbert RJ. A four-year longitudinal study of dental student learning styles. J Dent Educ 1987;51(4):175-81.

48. Murphy RJ, Gray SA, Straja SR, Bogert MC. Student learning preferences and teaching implications. J Dent Educ 2004;68(8):859-66. 
49. Zemsky R, Massey WF. Thwarted innovation: what happened to e-learning and why. A final report for the WeatherStation Project. West Chester, PA: The Learning Alliance for Higher Education at the University of Pennsylvania, 2004. At: www.irhe.upenn.edu/ WeatherStation.html. Accessed: January 2006.

50. Szulanski G. The process of knowledge transfer: a diachronic analysis of success. Org Behav Hum Decision Processes 2000;82(1):9-27.

51. Tyre MJ, Orlikowski WJ. Windows of opportunity: temporal patterns of technological adaptation in organization. Org Sci 1994;5(1):98-118.

52. Zucker LG. The role of institutionalization in cultural persistence. Am Sociol Rev 1977;42:726-43.
53. Szulanski G. Exploring internal stickiness: impediments to the transfer of best practice within the firm. Strat Management J 1996;17:27-43.

54. Albanese MA, Mitchell S. Problem-based learning: a review of the literature on its outcomes and implementation issues. Acad Med 1993;68:52-81.

55. Berkson L. Problem-based learning: have the expectations been met? Acad Med 1993;68(10 Suppl):S79-S88.

56. Vernon DTA, Blake RL. Does problem-based learning work? A meta-analysis of evaluative research. Acad Med 1993;68:550-63.

57. Saarinen-Rahiika H, Binkley JM. Problem-based learning in physical therapy: a review of the literature and overview of the McMaster University experience. Phys Ther 1998;78:195-207. 